\title{
O PIBID DE GEOGRAFIA E SUA IMPORTÂNCIA NO PROCESSO DE FORMAÇÃO PROFISSIONAL DOCENTE DO CURSO DE LICENCIATURA EM GEOGRAFIA- IFRN/CNAT
}

\section{THE PIBID OF GEOGRAPHY AND ITS IMPORTANCE IN THE PROCESS OF VOCATIONAL TRAINING IN THE GEOGRAPHY COURSE IN IFRN / CNAT}

\author{
Jeam Claude de Souza Gomes ${ }^{1}$; João Paulo Teixeira Viana ${ }^{2}$; Rebecka de França ${ }^{3}$ Maria do \\ Socorro Pessoa Fé ${ }^{4}$; Maria Cristina Cavalcanti de Araújo ${ }^{5}$
}

\section{RESUMO}

O presente trabalho tem por objetivo avaliar a importância do Programa Institucional de Bolsas de Iniciação à Docência - PIBID para a formação e prática docente dos licenciandos e egressos do curso de Licenciatura em Geografia do IFRN- CNAT. O PIBID, elaborado pela Fundação Coordenação de Aperfeiçoamento do Ensino Superior-CAPES, tem como objetivo fomentar a iniciação à docência e contribuir para o aperfeiçoamento da formação de docentes em nível superior, contribuindo com a melhoria de qualidade da educação básica pública brasileira. Nesse sentido, propõe-se, como objetivos da pesquisa entender a concepção e os objetivos do PIBID; investigar a percepção do licenciando em geografia sobre o programa; enaltecer a importância do investimento em políticas educacionais e dar visibilidade ao Programa de Iniciação à Docência. Para a efetivação da pesquisa, será realizada a revisão bibliográfica de textos, artigos e anais referentes ao ensino superior e ao PIBID, análises da Lei de Diretrizes e Bases da Educação Nacional - LDB e do Decreto $n^{\circ}$ 7.219/2010 que cria o PIBID, bem como dos Relatórios do PIBID de Geografia IFRN-CNAT.

Palavras-Chave: Ensino Superior. Iniciação à Docência. Formação Docente. Geografia

\begin{abstract}
The present study aims to evaluate the importance of the Institutional Program of Initiation Grants to Teaching - PIBID for the training and teaching practice of the graduates and graduates of the Degree in Geography of the IFRN-CNAT. The PIBID, developed by the Coordination Foundation for the Improvement of Higher Education - CAPES, aims to foster the initiation of teaching and contribute to the improvement of the training of teachers at a higher level, contributing to the improvement of the quality of Brazilian public basic education. In this sense, it is proposed, as objectives of the research, to understand the conception and the objectives of PIBID; investigate the licensee's perception of the program in geography; highlight the importance of investing in educational policies and give visibility to the Initiation to Teaching Program. To carry out the research, a bibliographical review of texts, articles and annals regarding higher education and PIBID, analyzes of the Law of Directives and Bases of National Education - LDB and of Decree No. 7,219 / 2010 that creates PIBID, will be carried out. and of the Reports of the PIBID of Geography IFRN-CNAT. In addition, forms will be applied with graduates and graduates participating in PIBID-Geography.
\end{abstract}

Keywords: Higher education. Initiation to Teaching. Teacher Training. Geography.

\footnotetext{
${ }^{1}$ Licenciatura em Geografia, IFRN, jeanclaude.14@ hotmail.com

${ }^{2}$ Licenciatura em Geografia, IFRN, jpviana25@yahoo.com.br

${ }^{3}$ Licenciatura em Geografia, IFRN, atransparenciarn@outlook.com

${ }^{4}$ Licenciatura em Geografia, IFRN, socorropessoafe73@gmail.com

${ }^{5}$ Doutora em Recursos Naturais, IFRN, cristina.cavalcanti@ifrn.edu.br
} 


\section{INTRODUÇÃO}

As políticas públicas educacionais no Brasil vêm sendo ampliadas ao longo de muitas décadas com o objetivo de preparar o país para ser uma nação emancipada. A tendência em educação tem sido pensar e discutir o papel da Educação na construção da cidadania como ferramenta imprescindível para a relação do sujeito com o mundo.

Cabe à educação garantir a aprendizagem de saberes e habilidades necessárias para a vida em sociedade, favorecendo ao aluno capacidade para o desenvolvimento da autonomia, espírito investigativo, dando sentido e significado aos seus conhecimentos. Por meio da aprovação da Constituição Federal em 1988, o financiamento da educação pública passou a ser prioridade, dessa forma o investimento em programas educacionais no país deve sempre estar na pauta dos governantes, isto porque a educação é um direito todos e todas, tendo papel fundamental na formação cidadã.

Sendo assim e sabendo o quão relevante é a educação para sociedade, é fundamental que o Estado invista com maior intensidade em políticas educacionais que fortaleça e estimulem a prática e formação docente no país, bem como a melhoria do ensino nas escolas da rede pública, para que assim a educação seja de fato um direito legado a todos.

Diante desse contexto, o presente artigo objetivo discutir e apontar, por meio de reflexões analíticas, a importância do Programa Institucional de Bolsa de Iniciação à Docência (PIBID) para a formação e prática docente dos licenciandos e egressos do curso de Licenciatura em Geografia, do Instituto Federal do Rio Grande do Norte - Campus-Natal/Central.

Dessa forma pretende-se buscar identificar qual a percepção que os licenciandos e egressos apresentam sobre a importância do processo de formação docente a partir das ações e atividades vivenciadas no referido programa.

\section{O PROGRAMA INSTITUCIONAL DE BOLSAS DE INICIAÇÃO A DOCÊNCIA}

Conforme disposto no DECRETO No 7.219, DE 24 DE JUNHO DE 2010, institucionaliza e dá as diretrizes que orientam como os bolsistas desempenharão suas atividades e o como PIBID funcionará, conforme versa o artigo 1 do decreto como conceito chave de propriedade para o programa, onde diz:

Dispõe sobre o Programa Institucional de Bolsa de Iniciação à Docência PIBID e dá outras providências.

O PRESIDENTE DA REPÚBLICA, no uso das atribuições que the confere o art. 84, inciso IV, da Constituição, e tendo em vista o disposto no art. $2^{\circ}, \S$ $2^{\circ}$, da Lei $n^{\circ} 8.405$, de 9 de janeiro de 1992 ,

DECRETA: Art. $1^{\circ} \mathrm{O}$ Programa Institucional de Bolsa de Iniciação à 
Docência - PIBID, executado no âmbito da Coordenação de Aperfeiçoamento de Pessoal de Nível Superior - CAPES, tem por finalidade fomentar a iniciação à docência, contribuindo para o aperfeiçoamento da formação de docentes em nível superior e para a melhoria de qualidade da educação básica pública brasileira. (BRASIL, 2010).

Assim, o programa tem sido suporte principal que unia as secretarias estaduais e municipais de educação e as universidades públicas e os institutos federais, onde futuros docentes, tem contato não apenas com a sala de aula, mas com o chão da escola, conhecendo a realidade e desafios da educação públicas brasileira. Desta forma o programa representa o momento de afirmação da carreira docente.

O PIBID tem como uma de suas estratégias a melhoria o ensino nas escolas públicas em que o Índice de Desenvolvimento da Educação Básica (Ideb) estava abaixo da média nacional, de 4,4. O programa apresenta objetivos secundários que são fundamentais para realização e execução do programa nas escolas, esses objetivos segundo o edital MEC/CAPAS/FNDE 2007 são:

I-Valorizar o magistério; II-Incentivar a formação de docentes em nível superior para a educação básica; III-Promover a melhoria da qualidade da educação básica; IV-Incentivar a articulação entre instituições superiores e as de formação básica; V- Elevar a qualidade da formação de professores; VIEstimular a integração da educação superior com a educação básica; VIIPromover a elevação da qualidade do ensino nas escolas da rede públicas; VIII-Fomentar metodologias e práticas docentes inovadoras que orientem para a superação de problemas no processo ensino- aprendizagem; IX-Valoriza o espaço da escola pública como campo de experiência na formação de professores; X-Proporcionar ao graduando a participação em ações metodológicas inovadoras e articuladas com a realidade local da escola (BRASIL, 2007).

Por meio destes objetivos, é possível notar que o PIBID procura aliar respostas a três necessidades brasileiras: primeiro, melhoria do aprendizado de alunos da educação básica, segundo aperfeiçoamento e terceira formação/capacitação docente. No primeiro edital do programa, em 2007, participaram apenas Instituições de ensino superior federais (IFES) onde seus projetos iniciais destinavam-se preferencialmente a área de extas com foco preferencial no ensino de nível médio.

Vales ressaltar que para ser bolsista do programa era necessário o aluno ser preferencialmente oriundo de escola públicas, estando matriculado em qualquer período dos cursos de licenciaturas, o candidato a bolsa era avaliado através do seu rendimento no curso, como também pela carta de motivação. Desde então diversas ações, decretos e portarias foram sendo inseridas a legislação do programa. 
Essas ações foram importantes na democratização do programa, estendendo a participação de cursos, ampliando números de bolsas e inseridos as escolas municipais ao quadro de participação do PIBID, outra mudança significativa foi a inclusão de escolas com altos índices de rendimentos (IDEB), onde antes apenas escolas abaixo da média podiam participar do programa, a inserção de participantes do PROUNI.

O segundo edital lançado em 2009 amplia o número de IES públicas estaduais e por meio da portaria $\mathrm{n}^{\mathrm{o}} 1.243$, aumenta os valores de bolsas dos participantes de programas de formação inicial e continuada de professores. É notório que no período que vai de 2007 criação do PIBID até 2009 lançamento do segundo edital o programa se democratizou, agregando novas instituições e aumentado o número de bolsas.

Em abril de 2010 é lançado o edital nº18/2010, este por sua vez muda a redação de alguns trechos da portaria, ampliando as áreas de conhecimento atendidas pelo PIBID, como por exemplo licenciaturas que atendam projetos interdisciplinares e licenciatura em pedagogia com enfoque para alfabetização em classe, incluindo a EJA, assim como exposto no Decreto $\mathrm{n}^{\circ}$ 7.219, de 24 de julho de 2010, afirmando que “O PIBID atenderá à formação em nível superior de docentes para atuar nos níveis infantil, fundamental e médio da educação básica, bem como na educação de pessoas com deficiência, jovens e adultos, comunidades quilombolas, indígenas e educação no campo".

Desta forma o pibidiano com essa nova configuração pode atuar nos diversos níveis e modalidades da educação, o que representou uma maior experiencia da vivência escolar. Ainda no ano de 2010 é criado o PIBID diversidade, voltado para alunos da educação do campo e comunidades indígenas. Em 2011 e 2012 os editais nº 1/2011 CAPES e nº 11/2012 CAPES, assim como a portaria $n^{\circ} 96 / 2013$ CAPES, objetivavam fazer chamadas públicas para aquelas instituições, que tinha o interesse em ampliar e cadastra novos projetos.

Já em 2013 com o edital 61/2013 CAPES, ocorre uma ampliação numérica e geográfica do programa em especial a adesão as instituições do setor privado. Nunes, (2014, p. 592) ao avaliar o programa no ano de 2013 afirma que:

em 2013 o programa, passa por uma ampla reformulação e uma forte expansão quantitativa pode ser percebida a partir da mais recente seleção do programa, convocada pelo Edital Capes n 61/2013 (CAPES, 2013): em abril de 2014, 81.177 mil bolsas foram pagas por meio do Sistema de Acompanhamento de Concessões da

Capes - SAC, das quais 65.928 mil são destinadas a licenciandos (CAPES, 2014). Em 2009, segundo ano de execução do programa, o número de bolsistas oriundos da primeira seleção - ocorrida em 2007 - era de 3.088 no total, conforme o Relatório de Gestão da Diretoria de Educação Básica Presencial DEB (CAPES, 2012). Isto corresponde a um crescimento de aproximadamente 26 vezes no total geral de bolsistas em cinco anos. 
Percebe-se então o quão grande foi a expansão do programa desde 2007, porém é importante frisar que há um desfoque no programa já que no início o objetivo era específico para instituições públicas. Mesmo com a perspectiva de democratizar o programa percebe-se que na realidade ocorre uma fragmentação do programa para mais de uma esfera.

No ano de 2016 é criada a portaria nº46 que altera o regulamento do PIBID, principalmente em seus objetivos, onde ocorreu a tentativa de fazer uma junção do programa com outros, desta forma ocorreram diversos protestos e ações do FORPIBID para barra esta portaria, visto que ela fere os objetivos do pibid relacionados a formação inicial docente. Porém em junho de 2016, surge outra portaria que revoga a anterior, com vistas a não mais atender aos objetivos da formação inicial docente.

A partir daí não foram estabelecidas novas normatização, até que no ano de 2017 o programa sofre com corte de bolsas e ameaças de cancelamento, onde foram realizadas inúmeras ações do FORPIBID (fórum nacional do PIBID) para barrar essas ameaças e cortes de verbas. Um exemplo desta situação é o próprio PIBID da licenciatura em geografia que desde o ano de 2014 não recebeu mais nenhum material para realização de atividades, o que no início do programa era bem diferente. Sendo assim de dezembro de 2017 até meados de janeiro de 2018 os bolsistas do programa viveram a expectativa se o PIBID seria cancelado ou não. Em fevereiro de 2018 ocorreu a suspensão do programa onde este fator representou uma ameaça a formação inicial de professores no Brasil.

A CAPES então afirma que o programa está suspenso para que seja reformulado um novo edital, visto que o programa apresentava defasagens. Então no ano de 2018 ressurge o PIBID, por meio de um novo edital ( $n^{\circ}$ 7/2018 capes) uma das primeiras alterações foi em relação ao tempo de curso que o bolsista deverá ter para pleitear uma vaga no programa segundo o edital só poderá se inscrever estudantes que estiverem matriculados na primeira metade de curso, antes não havia esta restrição.

Este fator deve-se ao novo programa do MEC, a Residência Pedagógica, que recebe estudantes matriculados a partir do $5^{\circ}$ período de curso em paralelo a realização dos estágios docente. Em relação aos objetivos o novo edital afirma:

I.incentivar a formação de docentes em nível superior para a educação básica; II. contribuir para a valorização do magistério; III. elevar a qualidade da formação inicial de professores nos cursos de licenciatura, promovendo a integração entre educação superior e educação básica; IV. inserir os licenciandos no cotidiano de escolas da rede pública de educação, proporcionando-lhes oportunidades de criação e participação em experiências metodológicas, tecnológicas e práticas docentes de caráter inovador e interdisciplinar que busquem a superação de problemas identificados no 
processo de ensino-aprendizagem; V. incentivar escolas públicas de educação básica, mobilizando seus professores como co-formadores dos futuros docentes e tornando-as protagonistas nos processos de formação inicial para o magistério; e VI. contribuir para a articulação entre teoria e prática necessárias à formação dos docentes, elevando a qualidade das ações acadêmicas nos cursos de licenciatura. (BRASIL,2018)

Percebe-se que a uma harmonia em relação aos objetivos de ambos os editas todos enfatizam o papel do programa no incentivo a formação docente, valorização do magistério e algo de grande importância a melhoria da educação básica no país. Outro a fator de alteração foi a seleção dos bolsistas onde nessa nova fase do PIBID todos deverão ter cadastro na plataforma freire da capes e MEC. Mesmo assim não sabemos ao certo se o programa ira sobreviver visto que a própria CAPES afirmou que se em 2019 os investimentos da educação não forem reformulados as bolsas de programas com o PIBID serão suspensas, assim como também não se sabe-se se com o advento da residência pedagógica o programa ira sobreviver, visto que quando se fala em investimento para educação o próprio governo afirma que são insuficientes, então não se pode afirmar ao certo se os dois programas vão permanecer apenas o futuro nos dirá.

\section{METODOLOGIA}

Para que tais objetivos fossem alcançados o presente trabalho foi fundamentado em pesquisa de cunho exploratório que buscaram uma aproximação ao problema, lapidação de ideias e estímulo ao surgimento de possíveis intuições.

Foi realizado levantamento bibliográfico em obras, artigos e anais relacionados à temática e documentos norteadores do programa, que foram de grande importância para a compreensão dos objetivos do PIBID, sua criação e elucidar o quanto o mesmo foi relevante para o processo e incentivo a formação docente. No que se refere aos instrumentos de pesquisa foi elaborado formulário eletrônico na ferramenta google doc's, com questões relacionadas às experiências a partir da participação no PIBID, mais precisamente, sobre os impactos e impressões das ações/atividades vivenciadas até então no Projeto em sua formação profissional, bem como possíveis dificuldades encontradas e perspectivas para a continuidade dele. Ao todo foram respondidos 100 formulários entre os meses de março á maio, não foi um número expressivo visto que muitos que participaram do programa são egressos o que dificultou um alcance maior de entrevistados

\section{RESULTADOS E DISCUSSÃO}


Este tópico é destinado a análise da importância do PIBID GEOGRAFIA/IFRN- CNAT para a formação docente dos ex-bolsista do programa, para tanto foi necessário se ater a um questionário pré-estruturado através da plataforma "google Doc's" com a finalidade de facilitar a participação do entrevistado. Iniciamos procurando investigar qual a situação do entrevistado (ex-bolsista) no curso de licenciatura em geografia (IFRN-CNAT) se o curso já foi concluído ou se ele está cursando conforme os resultados obtidos estão representados no gráfico 01.

Grafico 01- Situação do ex-bolsista no curso de licenciatura em Geografia (IFRN-CNAT)

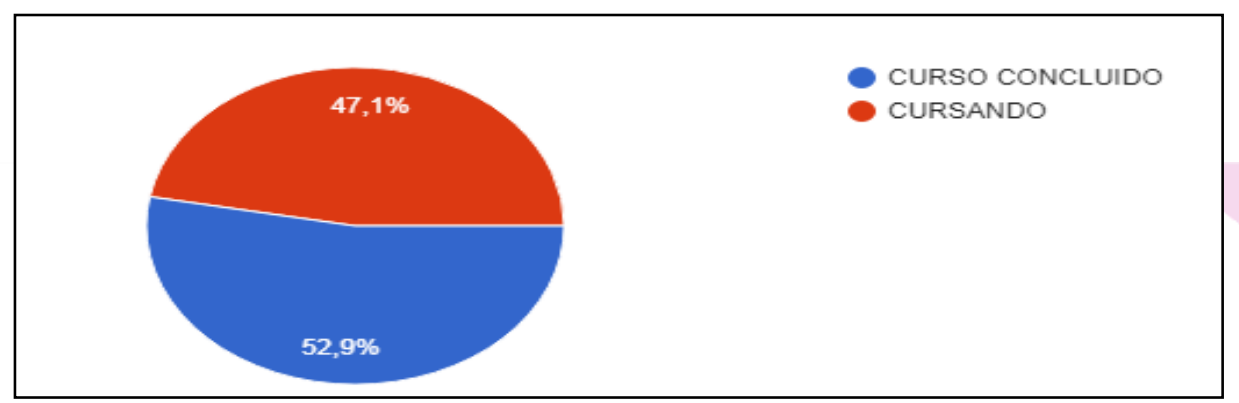

Fonte: O próprio autor

É interessante notar que cerca de $47 \%$ dos entrevistados ainda estão matriculados no curso, muitos deles dependem de incentivos para continuar no curso, tanto financeiro como motivacional. Um dos entrevistados afirma que "o PIBID antecipou o friozinho da barriga que sentiria nos estágios, me preparou com relação a como lidar com a turma, e me aproximou da docência, sem ele, não teria me saído muito nas atividades de seminários, além do mais, proporciona uma revisão dos assuntos que vemos na academia, está no Geopibid também auxiliou a questionar as mudanças na educação e contribuir para que isso aconteça”. Outro afirmou que "Foi fundamental, pois na época meu pai estava desempregado e não podia custear o transporte para o deslocamento para a faculdade, assim como compra de material e inscrições de congresso. Logo, foi por intermédio da bolsa que consegui concluir o curso”.

A parti desses fragmentos percebemos o quão relevante é o programa para o licenciando. Outro fator que procurou-se investigar é se de fato o programa pode ser considerado um fator determinante para melhorar a qualidade da educação básica no Brasil, os resultados obtidos serão retratados no gráfico 02 :

Grafico 02- O PIBID pode ser considerado um fator determinante para melhorar a qualidade da 


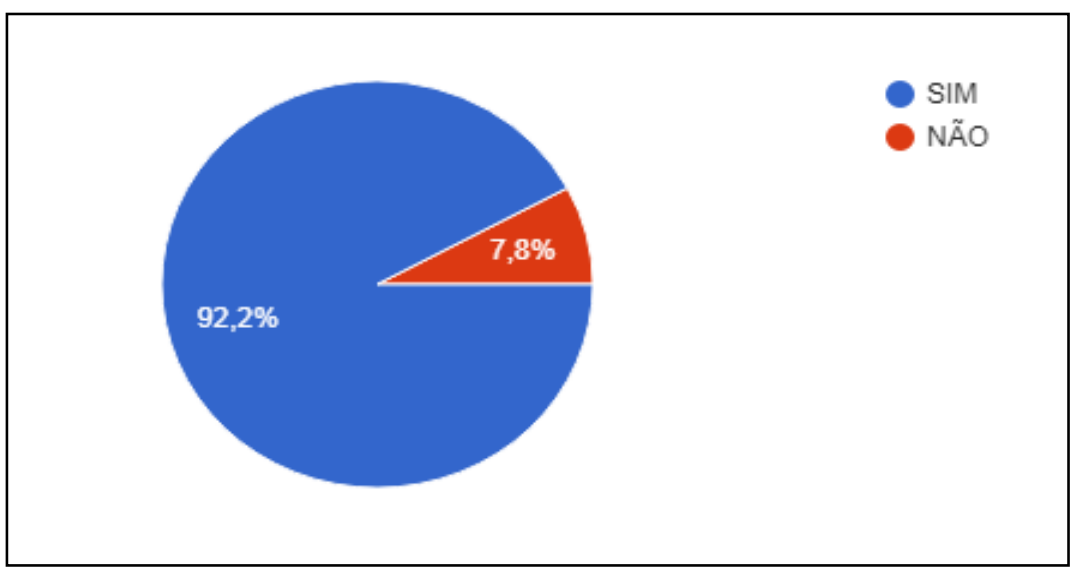

Fonte: O próprio autor

Um dos objetivos do programa é melhorar a qualidade da educação básica no Brasil, segundo os entrevistados $92 \%$ afirma que o PIBID pode sim ser considerado um fator determinante para melhora a qualidade do ensino básico. Outro questionamento importante foi verificar se a participação no PIBID/Geografia reforça/reforçou seu desejo de permanecer no curso de Licenciatura? Os resultados serão descritos no gráfico 03:

Gráfico 03- A participação no PIBID/Geografia reforça/reforçou seu desejo de permanecer no curso de Licenciatura?

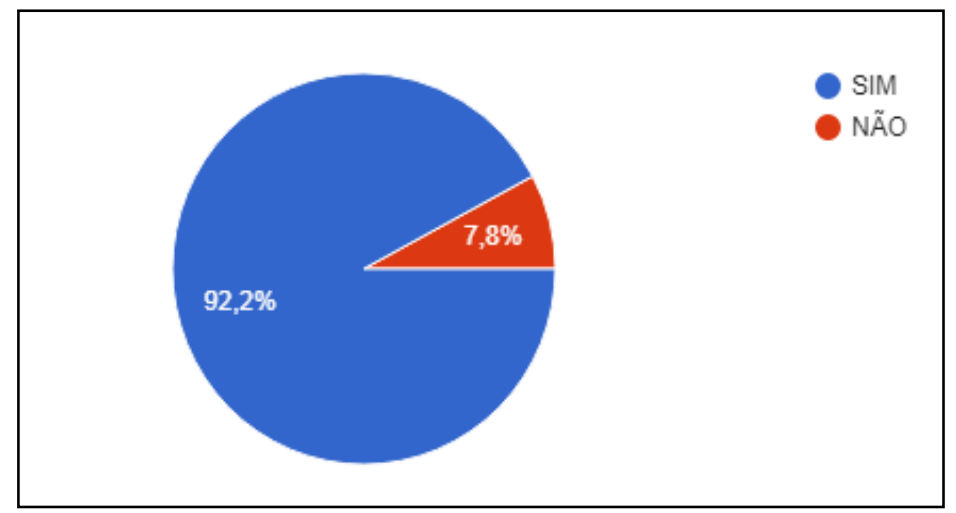

Fonte: O próprio autor

Dos entrevistados 92\% afirmam que o PIBID reforçou o desejo de permanecia no curso de licenciatura geografia, desta forma é importante reforça o papel que o programa tem para manutenção e permanecia de alunos nos cursos de licenciatura, um dos entrevistados evidenciou que o programa "propiciou a possibilidade de permanecer no curso sem precisar trabalhar em outra área, o que sem dúvida foi muito importante para a conclusão do curso, uma vez que como participante da bolsa, pude me dedicar ao curso”. Pode-se indagar que o PIBID pode ser um forte aliado na redução dos números de evasões nos cursos de licenciatura. 
Dentro desses fatores foi importante destacar também se a qualidade do ensino na escola em que o bolsista atuou foi afetada pelas ações do PIBID/Geografia? Os resultados serão demostrados a seguir no gráfico 04 :

Gráfico 04- A qualidade do ensino na escola em que o bolsista atuou foi afetada pelas ações do PIBID/Geografia?

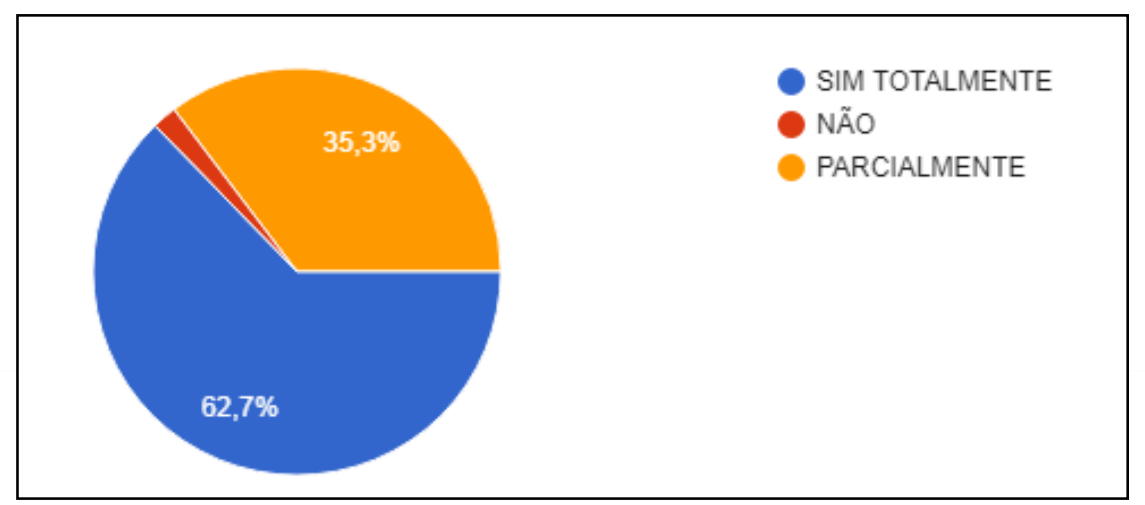

Fonte: O próprio autor

O gráfico acima demostra de $62 \%$ dos entrevistados afirmam que a qualidade do ensino na escola em que atuou como bolsista foi afetada pelas ações desenvolvidas no PIBID, porém $35 \%$ dizem que afetou parcialmente um dos entrevistados evidenciou que " a inserção articulada do Programa em todas as disciplinas ofertadas pela escola e Licenciaturas pra que possa ter mais envolvimento entre PIBID e escola que recebe os bolsistas. Trabalho de integração de modo articulado". Outro entrevistado afirmou "faltou de materiais para se realizar as atividades nas escolas".

É importante pensar o programa de maneira interdisciplinar onde as ações propostas possam interagir com o currículo escolar de forma integrada, quanto a falta de materiais para as escolas segundo coordenadores institucionais do IFRN- CNAT desde 2010 o programa deixou de receber materiais como folhas, cartolinas etc.

Outra questão importante para pesquisa foi se de fato a participação no PIBID/Geografia mudou minha visão sobre a profissão de professor de Geografia? O resultado pode ser observado no gráfico 05 :

Gráfico 05- A participação no PIBID/Geografia mudou minha visão sobre a profissão de professor de Geografia? 


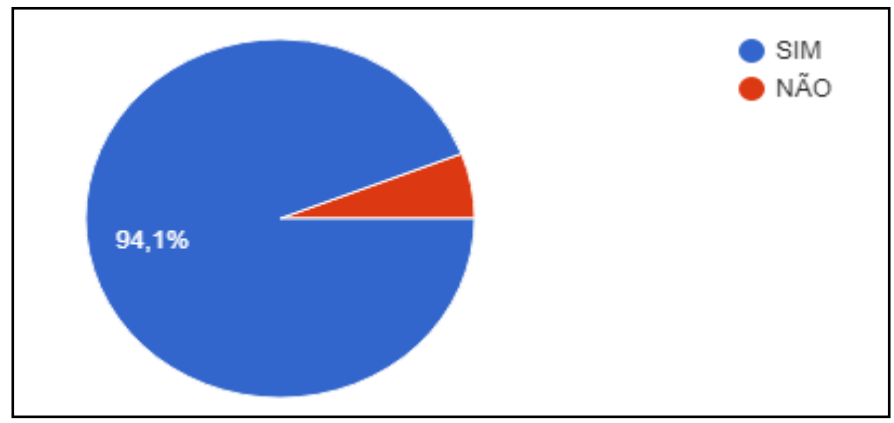

Fonte: o próprio autor

Pode-se observar que $94 \%$ dos entrevistados confirmam que ter participado do programa mudou sua visão de ser professor de geografia, um dos entrevistado deixou claro que "estava disposto a desistir do curso, sem perspectiva para o futuro, ao entrar no programa notei que de fato esta na profissão correta e pude me apaixonar mais ainda pela docência na geografia".

Mas uma vez fica evidente que o programa tem forte influência dentro do processo de formação docente, ele aproxima o licenciando a realidade da escola, possibilitando a chance dele confirma e afirma seu desejo de seguir a carreira docente.

A pergunta mais importante é norteadora do presente artigo foi qual a importância do PIBID no processo de formação docente, como pode ser observado no gráfico $06,100 \%$ dos entrevistados afirma que foi muito importante.

Gráfico 06- A importância do PIBID no processo de formação docente

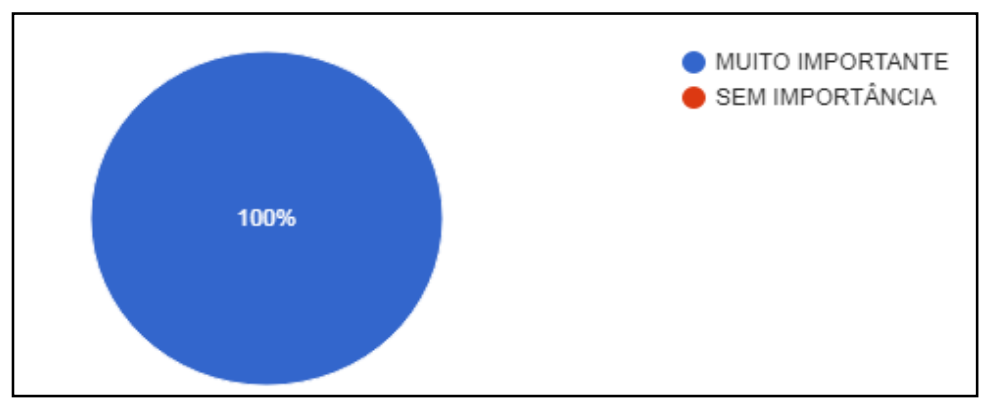

Fonte: o próprio autor

Desta forma fica evidente que para os 100 entrevistados o PIBID é sim de grande importância para o processo de formação docente. Os entrevistados acreditam no programa de uma forma muito além da bolsa e do valor oferecido, mas da possibilidade de crescimento profissional, do outro lado temos a questão de que muitos dos bolsistas e egressos têm nesse valor a possiblidade de continuar seus estudos na licenciatura, afetando assim no processo de ensino e aprendizagem do profissional e respectivamente na aplicação das ações no espaço escolar. 


\section{CONSIDERAÇÕES FINAIS}

Em suma, tendo em vista, que a intenção desta pesquisa foi compreender a importância do PIBID na formação acadêmica do licenciando, pode-se dizer que é fundamental que o discente vivencie a realidade escolar através de projetos de iniciação à docência, pois, a partir dele é possível fazer a aproximação teórica do campo empírico. Nesse contexto, fica evidente que o projeto propicia uma formação diferenciada por meio da prática compensando as lacunas ainda existentes na grade curricular do curso de licenciatura.

Portanto, a formação acadêmica através do projeto PIBID dá-se de maneira desafiadora e instigante, pois, exige do discente empenho, dedicação e colaboração para a efetuação das atividades propostas.

Diante do exposto nesta pesquisa com os principais atores do projeto, observa-se que o PIBID proporcionou incentivos com relação à pesquisa e a formação docente crítica-reflexiva à medida que torna a aprendizagem significativa, baseando-se nos diversos contextos e conflitos, que permeiam o campo educativo.

\section{REFERÊNCIAS}

BRASIL. Constituição da República Federativa do Brasil. 35ª ed. Brasília: Biblioteca Digital da Câmara de Deputados, 2012.

BRASIL. Lei de Diretrizes e Bases da Educação Nacional - Lei 9394 de 1996. Brasília, 1996.

BRASIL. Secretaria de Educação Fundamental. Parâmetros curriculares nacionais: matemática. Brasília, DF, 1998. 148 p. Disponível em:

<ftp://ftp.fnde.gov.br/web/pcn/05_08_matematica.pdf>. Acesso em: 01 mai. 2018.

BRASIL. Secretaria de Educação Média e Tecnológica. Parâmetros curriculares nacionais: ensino médio. Brasília, DF, 2000. 109 p. Disponível em:

http://portal.mec.gov.br/seb/arquivos/pdf/blegais.pdf. Acesso em: 01 mai. 2018.

CAPES. Pibid - Programa Institucional de Bolsa de Iniciação à Docência. Brasília:

Fundação CAPES, 2008. Disponível em < http://www.capes.gov.br/educacao-

basica/capespibid>. Acesso em 15 de dezembro 2017.

MEC - MINISTÉRIO DA EDUCAÇÃO. Disponível em:<www.mec.gov.br.>Acesso em: 25 de agosto de 2018.

NUNES, D. F.; SANTANA, L. L.; SILVA, K. A. C. P. C. Programas de formação inicial de professores: um estudo de caso sobre o Pibid no Distrito Federal. Educação, Santa Maria, v. 39, n. 3, p. 589-604, set./dez. 2014. 